\title{
Article \\ Effects of Multi-Axial Compression on the Mechanical and Fretting Wear Properties of Ti-45Nb Alloys
}

\author{
Zhuoqing $X u^{1,+}$, Nan $\mathrm{Hu}^{2,3,+}$, Yuan $\mathrm{Lu}^{1}$ and Xiaochang $X \mathrm{u}^{1, *(D)}$ \\ 1 School of Materials Science and Engineering, Central South University, Changsha 410083, China; \\ 183112121@csu.edu.cn (Z.X.); 193112159@csu.edu.cn (Y.L.) \\ 2 National Innovation Center for Advanced Medical Devices, Shenzhen 518100, China; nan.hu@siat.ac.cn \\ 3 Center for Human Tissues and Organs Degeneration, Shenzhen Institutes of Advanced Technology, \\ Chinese Academy of Sciences, Shenzhen 518055, China \\ * Correspondence: xuxiaochang@csu.edu.cn; Tel.: +86-13787797327 \\ + Authors have contributed equally to this work.
}

Citation: Xu, Z.; Hu, N.; Lu, Y.; Xu, X. Effects of Multi-Axial Compression on the Mechanical and Fretting Wear Properties of Ti-45Nb Alloys. Metals 2021, 11, 454. https://doi.org/ $10.3390 /$ met11030454

Academic Editor: Maciej Motyka

Received: 13 February 2021

Accepted: 3 March 2021

Published: 10 March 2021

Publisher's Note: MDPI stays neutral with regard to jurisdictional claims in published maps and institutional affiliations.

Copyright: (c) 2021 by the authors. Licensee MDPI, Basel, Switzerland. This article is an open access article distributed under the terms and conditions of the Creative Commons Attribution (CC BY) license (https:/ / creativecommons.org/licenses/by/ $4.0 /)$.

\begin{abstract}
Biocompatible $\beta$-type Ti- $45 \mathrm{Nb}$ alloy with a low elastic modulus is promising in alleviating the stress shielding effect of Ti-based hard-tissue replacement implants. In this work, the ultra-finegrained (UFG) microstructures with different grain sizes were prepared by multi-axial compression (MAC) processing of Ti- $45 \mathrm{Nb}$ alloys, and the mechanical properties and the fretting wear properties of Ti-45Nb alloys in different grain sizes were investigated. The results show that the yield strength and ultimate tensile strength of the sample processed by 27 passes MAC increase by $76 \%$ and $91 \%$, respectively, with an elongation of more than $9 \%$. After MAC processing, the friction coefficient and volume wear rate gradually decrease. In addition, before MAC processing, the Ti- $45 \mathrm{Nb}$ sample shows a wear mechanism of severe adhesive wear, oxidative wear and fatigue delamination; while after MAC processing, the wear mechanism switches to abrasive wear and slight adhesive wear with slight oxidative wear, indicating that grain refinement helps to improve the anti-fretting properties of $\mathrm{Ti}-45 \mathrm{Nb}$ alloys.
\end{abstract}

Keywords: severe plastic deformation; Ti-45Nb alloys; implants; mechanical properties; fretting wear

\section{Introduction}

Although Ti and its alloys have been widely used for hard-tissue replacement applications, over the long term, its comparatively high elastic modulus will lead to a stress shielding effect that may result in aseptic loosening and other implant failure problems [1]. In recent years, $\beta$-type titanium alloys with a reduced elastic modulus have received extensive attention to address the problems related to the stress shielding effect, and Ti- $45 \mathrm{Nb}$ alloy shows the lowest elastic modulus ( $65 \mathrm{GPa})$ in the binary Ti-Nb system in the solid solution state [2,3]. Moreover, it does not contain toxic elements such as aluminum and vanadium that raise clinical concerns about biosafety [4].

However, an implant must fulfill multiple requirements in addition to reduced elastic modulus. Good mechanical properties and wear resistance are also needed. Fretting wear is the most frequently occurring mode of wear on implants, in which the implant moves in a small (micron-level) amplitude with respect to the adjacent human bone [5,6]. As a result, the osteolysis induced by wear particles is one of the most important causes of aseptic loosening [7], which can be potentially alleviated by severe plastic deformation (SPD) [8] SPD can reduce grain size and introduce a large number of dislocations by applying an extremely large strain to obtain an ultra-fine-grained (UFG) microstructure [9,10]. According to the Hall-Petch relationship and Archard formula [11-13], the reduced grain size can significantly improve the hardness, which can hopefully reduce the fretting wear on the surface of the implant [8]. Because Ti-45Nb alloys have a high content of $\beta$-stabilizing elements, SPD processing can maintain the single-phase microstructure and thus retaining 
the low elastic modulus [14]. Therefore, SPD processing of Ti- $45 \mathrm{Nb}$ alloys is expected to improve the strength, reduce fretting wear and simultaneously maintain a low elastic modulus. The most widely used SPD techniques are equal-channel angular pressing (ECAP) [15], high pressure torsion (HPT) [16] and multi-axial compression (MAC) [17], MAC processing has a high industrialization potential because it is easy to be implemented on the existing die forging facilities and MAC samples are in a comparatively larger size compared to HPT and ECAP samples [18,19].

To date, few studies have been carried out on the influence of SPD processing on the fretting wear behavior of Ti alloys. In addition, the effect of grain refinement on the wear performance of Ti alloys is still under debate, since there are many contradictory results: Stolyarov et al. processed commercial pure (CP) Ti with an average grain size of $0.1 \mu \mathrm{m}$ after 8 ECAP and ECAP + cold rolling and found that the UFG structure reduced adhesion component of the frictional force, consequently leading to lower friction coefficient (COF), which should in turn improve the wear property [20]; La et al. found that the wear mechanism of UFG Ti changed and the wear rate was reduced by $30 \%$ in a similar study, but the COF was similar to that of annealed coarse-grained (CG) Ti [21]. Long et al. combined high-energy ball milling and spark plasma sintering to process Ti-6Al-4V (TC4) alloys with CG structures, double-scale structures, and UFG structures and tested them with a ball-disk fretting wear device. It was found that grain size refinement reduced the COF and wear rate [22]. By contrast, Purcek et al. processed CP Ti with an average grain size of approximately $0.25 \mu \mathrm{m}$ by ECAP. They found that although UFG Ti was significantly strengthened, it did not improve its wear resistance [23]; Wang et al. processed $\mathrm{CP}$ Ti by HPT and reached the same conclusion, and they believe that this was due to the high reactivity of the Ti alloys with oxygen, and the oxidation layer achieved a dynamic equilibrium between continuous removal and regeneration, thus concealing the improvement of the wear resistance of the material by grain refinement [24]. It can be seen from these results that influence of grain refinement on the wear resistance of metallic materials is still unclear, therefore the underlying mechanisms needs to be further explored.

In this investigation, transmission electron microscopy (TEM), optical microscopy $(\mathrm{OM}), \mathrm{X}$-ray diffraction (XRD), scanning electron microscopy (SEM) and fretting wear tests were used to study the microstructural evolution of Ti- $45 \mathrm{Nb}$ alloys processed by MAC and its influence on the mechanical properties and fretting wear behaviors.

\section{Materials and Methods}

\subsection{Materials}

The Ti- $45 \mathrm{Nb}$ alloy used for this study was received as a bar with a diameter of $22 \mathrm{~mm}$ (Ningxia Orient Tantalum Industry Co. Ltd., Ningxia, China) and the chemical composition (Table 1) was determined by inductively-coupled plasma optical emission spectrometry (ICP-OES) on a Perkin Elmer OPTIMA 7000DV spectrometer (PE, Massachusetts, USA).

Table 1. Chemical composition of the Ti-45Nb alloy.

\begin{tabular}{cccccccc}
\hline Element & $\mathbf{T i}$ & $\mathbf{N b}$ & $\mathbf{O}$ & $\mathbf{N}$ & $\mathbf{H}$ & $\mathbf{C}$ & $\mathbf{F e}$ \\
\hline Content (wt \%) & Balance & 44.83 & 0.095 & 0.002 & 0.002 & 0.028 & 0.024 \\
\hline
\end{tabular}

Rectangular prism samples were cut into $10 \times 10 \times 15 \mathrm{~mm}$ dimensions by wire-cutting and then treated with a vacuum solution treatment at $933 \mathrm{~K}$ for $1 \mathrm{~h}$, followed by quenching in water to obtain a single-phase $\beta$ microstructure as a solid solution.

\subsection{MAC Processing}

At room temperature (RT), the rectangular prisms were compressed through the various passes along the $\mathrm{X}-\mathrm{Y}-\mathrm{Z}-\mathrm{X}$ axes to change the direction of compression to a total of 31 passes, in which microcracks occurred. Figure 1 shows the deformation schematic diagram. Different planes of the prism are colored in different colors, and the planes in the 
same color after the pressing and rotation during 1,2 and 3 passes are corresponding to the plane in the same color of the sample before MAC processing. The equivalent strain $\varepsilon$ of each pass is approximately 0.4 calculated using the formula [25]:

$$
\varepsilon=\ln \frac{h_{0}}{h}
$$

where $h_{0}=15 \mathrm{~mm}$ is the original height of the specimen, $h=10 \mathrm{~mm}$ is the height after deformation. A MoS 2 lubricant was used on each pass. Considering the comprehensive performance of the samples, the number of passes near the failure state was avoided, and the samples processed at $0,9,18$, and 27 passes were selected and named as MAC-0, MAC-9, MAC-18 and MAC-27 samples, respectively.

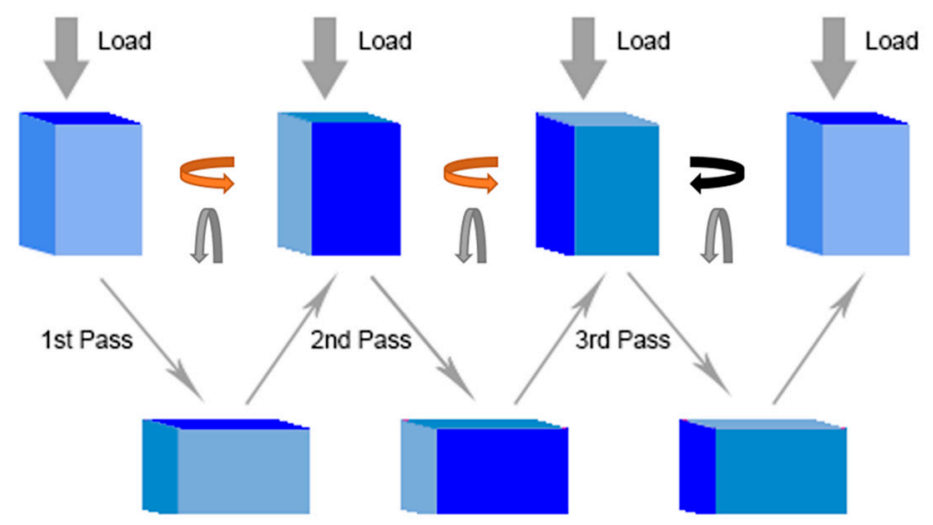

Figure 1. Schematic diagram of multi-axial compression.

\subsection{Microstructure and Mechanical Properties}

Bruker D8-Discover XRD (Bruker AXS GmbH, Karlsruhe, Germany) was used to determine the phase composition and calculate the densities of the dislocations. OLMPUSBH2 OM (Olympus, Tokyo, Japan) and TEM were used to investigate the microstructural evolution of the Ti-45Nb samples. The MAC-0 samples were carefully polished using SiC papers of grit size up to 2000 and then polished with colloidal silica suspensions of size up to $0.06 \mu \mathrm{m}$ mixed with $30 \% \mathrm{H}_{2} \mathrm{O}_{2}$. They were chemically etched with Kroll's reagent before the optical investigation. TEM investigations were carried out in a Philips Tecnai-G220 microscope (Philips, Eindhoven, The Netherlands) operated at a nominal accelerating voltage of $200 \mathrm{kV}$. The MAC-9, MAC-18, MAC-27 samples were cut along the vertical center plane of the last compression, thinned to below $80 \mu \mathrm{m}$ on both sides, and then processed by double spraying by twin-jet electropolishing in an electrolyte composed of 6 vol.\% $\mathrm{HClO}_{4}+34$ vol. $\% \mathrm{CH}_{3}\left(\mathrm{CH}_{2}\right)_{3} \mathrm{OH}+60$ vol. $\% \mathrm{CH}_{3} \mathrm{OH}$ with an applied potential of $30 \mathrm{~V}$ at approximately $30^{\circ} \mathrm{C}$.

Vickers hardness tests with a HV-1000 digital microhardness tester (Suzhou Haichuan Science and Education Equipment Co. Ltd., Suzhou, China) were carried out under an applied load of $0.5 \mathrm{~kg}$ for $15 \mathrm{~s}$ with 5 points measured on each site, and the average values and the standard deviation were taken. Tensile tests were performed at room temperature using a CMT 6103 microtensile test system (MTS, Minnesota, USA) with three samples tested for each condition.

\subsection{Fretting Test}

The Nano Test Vantange Alpha (Micro Materials Ltd., Wrexham, UK) uses the modular nano micro-movement option developed in recent years for nano indentation [26] with a lever device to amplify the piezoelectric motion to obtain greater amplitude. This is a new type of nano fretting abrasion test method that can carry out in situ wear research on the micron and nanoscales [27]. 
The fretting wear tests were conducted at room temperature (approximately $25^{\circ} \mathrm{C}$ ) and at a relative humidity of approximately $50 \%$. A spherical diamond indenter with a diameter of $25 \mu \mathrm{m}$ was chosen. The fretting amplitude was set to $\pm 250 \mu \mathrm{m}$ under a load of $30 \mathrm{mN}$. 3600 reciprocating friction tests were performed at a vibration frequency of $2 \mathrm{~Hz}$, and the COF curve was obtained.

The morphologies of the wear surfaces of the samples were examined using a Quanta200 SEM (FEI, Brno, Czech) in secondary electron image mode to clarify the operative wear mechanisms. Additionally, the two-dimensional and three-dimensional contours of the wear surfaces were obtained with a Wyko NT9100 surface profiler (Bruker AXS GmbH, Karlsruhe, Germany) and a Zeiss Axio LSM 700 laser scanning confocal microscope (Zeiss, Jena, German). The wear volume values were calculated using the model of Z. Doni [28], and the volume wear rates were calculated by the formula [12]:

$$
K=\frac{\Delta V}{W S}
$$

where $K$ is the volume wear rate, $\Delta V$ is the wear volume, $W$ is the load, and $S$ is the total sliding distance.

\section{Results and Discussion}

\subsection{Microstructure Evolution}

To confirm whether the $\beta$ single-phase structure of $\mathrm{Ti}-45 \mathrm{Nb}$ is retained during $\mathrm{MAC}$ processing, XRD detection was performed and are shown in Figure 2a. All the diffraction patterns only show peaks from $\beta$ single-phase, indicating that there was no phase transformation during MAC processing, therefore the elastic modulus of $\mathrm{Ti}-45 \mathrm{Nb}$ maintained at the low level of the solid solution state [3,29].

Large dislocation multiplication was caused by the MAC, and the dislocation density was calculated by the Williamson-Hall method through the diffraction peak broadening model caused by the grain refinement and microstrain [30]. The dislocation density of the MAC-0, the MAC-9, MAC-18, and MAC-27 samples has been listed in Table 2.

To further explore the evolution of the microstructure of the MAC process, OM and TEM were used to observe the microstructure of the samples before and after MAC processing. The CG microstructure of the solid-solution sample is shown in Figure $2 b$. The grains present a typical equiaxed structure, and the average grain size is approximately $15 \mu \mathrm{m}$.

The UFG microstructures of the MAC-9, MAC-18 and MAC-27 samples observed by TEM are shown in Figure 2c-k). The TEM images of the MAC-9 sample (Figure 2c-e) show a rather heterogeneous microstructure composed of rather strongly elongated grains with the long axis parallel to the shear direction and some irregular high-density dislocation entanglements, as well as dislocation lamellae that indicates that under the action of elastic strain energy, dislocations were in the process of evolving from an irregular entangled morphology to regular dislocation sheet-like structures and gradually became subgrain boundaries. Both bright-field (BF) and dark-field (DF) images can be used to estimate the grain size. It was observed that the subgrains were approximately $300 \mathrm{~nm}$ long, and they were approximately $50-80 \mathrm{~nm}$ wide. In the case of the MAC-18 sample (Figure $2 \mathrm{f}-\mathrm{h}$ ), the elongated grains were continuously separated and broken and gradually became approximately equiaxed subcrystals. At the same time, there were still dense dislocations inside the grains. The grain size was reduced to approximately $200 \mathrm{~nm}$ at this time, and the corresponding selected area electron diffraction (SAED) shows discontinuous diffraction rings, suggesting the coexistence of grains and subgrains. As the processing strain further increased at 27 passes (Figure 2i-k), the subgrains became more regular, and the grain size was reduced to below $100 \mathrm{~nm}$. It can be seen that the UFG structure can be processed by MAC, and the increase in the strain can promote the homogeneity of the UFG microstructure. 

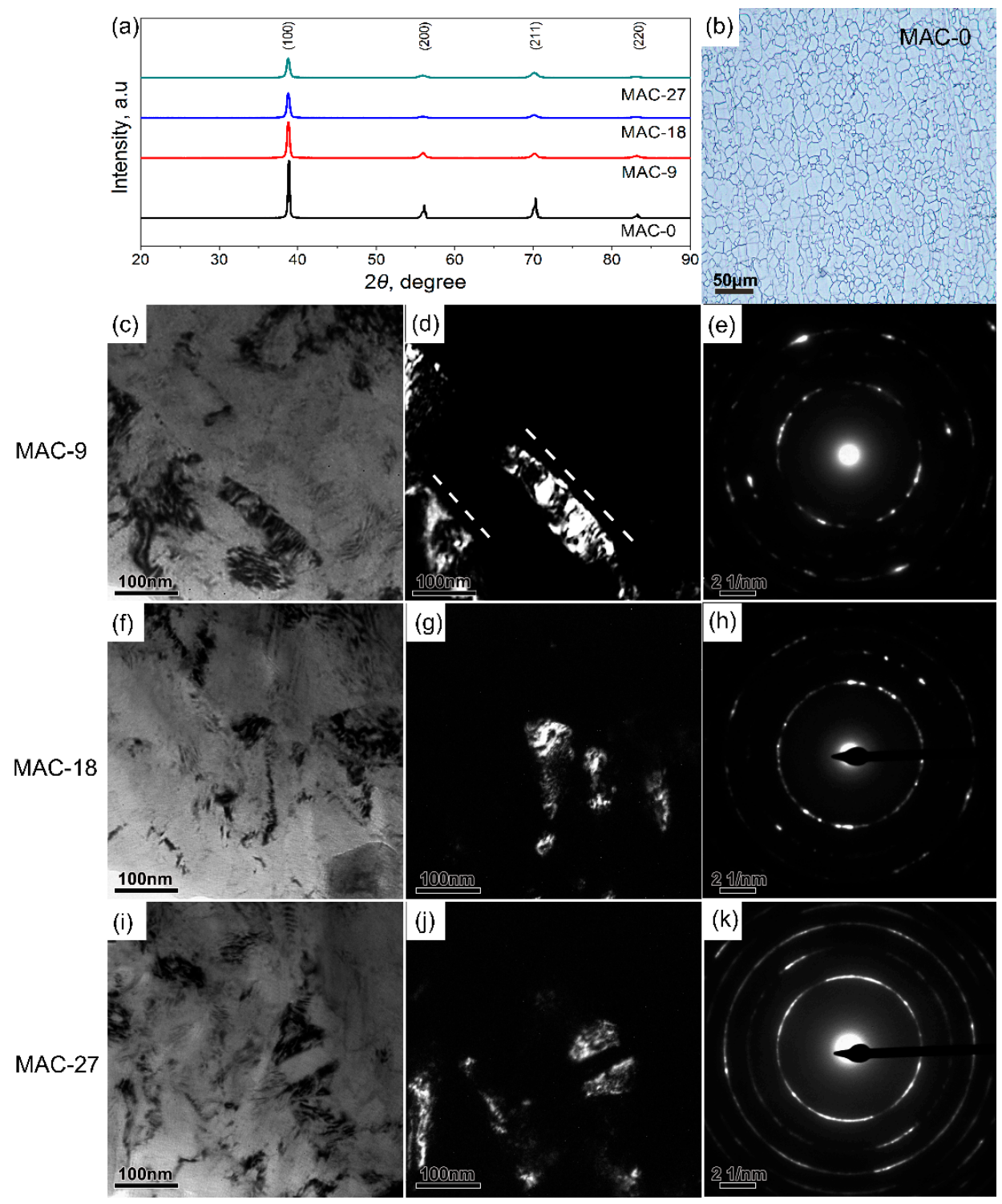

Figure 2. (a) XRD patterns of the Ti-45Nb samples: all peaks are for the $\beta$ phase; (b) OM photo of the MAC-0 sample; (c-e) TEM BF, DF, and SAED images of the MAC-9 sample; (f-h) TEM BF, DF, and SAED images of the MAC-18 sample; (i-k) TEM BF, DF, SAED images of the MAC-27 sample.

Table 2. Microstructure, mechanical and fretting wear properties of the Ti-45Nb samples.

\begin{tabular}{|c|c|c|c|c|}
\hline Sample & MAC-0 & MAC-9 & MAC-18 & MAC-27 \\
\hline Average grain size $(\mu \mathrm{m})$ & $\sim 15$ & $\sim 0.3$ & $\sim 0.2$ & $\sim 0.1$ \\
\hline UTS (MPa) & $410 \pm 13$ & $654 \pm 18$ & $699 \pm 14$ & $781 \pm 11$ \\
\hline YS (MPa) & $401 \pm 12$ & $595 \pm 23$ & $634 \pm 21$ & $707 \pm 19$ \\
\hline Elongation $\delta(\%)$ & $19.8 \pm 1.2$ & $13.5 \pm 1.7$ & $10.8 \pm 1.3$ & $9.2 \pm 1.0$ \\
\hline Reduction of area $\Psi(\%)$ & $77.9 \pm 4.6$ & $48.3 \pm 2.3$ & $37.8 \pm 1.9$ & $37 \pm 1.5$ \\
\hline Dislocation density $\rho\left(1 / \mathrm{m}^{2}\right)$ & $7.09 \times 10^{16}$ & $4.52 \times 10^{17}$ & $2.20 \times 10^{18}$ & $5.16 \times 10^{18}$ \\
\hline Hardness (Hv) & $144.5 \pm 3.0$ & $189.5 \pm 15.5$ & $222.7 \pm 6.2$ & $245.5 \pm 3.6$ \\
\hline Average COF & 0.424 & 0.403 & 0.397 & 0.39 \\
\hline Wear rate $\left(10^{-3} \mathrm{~mm}^{3} \cdot \mathrm{N}^{-1} \cdot \mathrm{mm}^{-1}\right)$ & 10.39 & 9.88 & 8.33 & 6.20 \\
\hline
\end{tabular}




\subsection{Mechanical Properties}

The stress-strain curves of the MAC-0, MAC-9, MAC-18, and MAC-27 samples from the micro-tensile tests are shown in Figure 3, and Table 2 lists the microstructure, mechanical properties and fretting wear properties of the Ti- $45 \mathrm{Nb}$ samples.

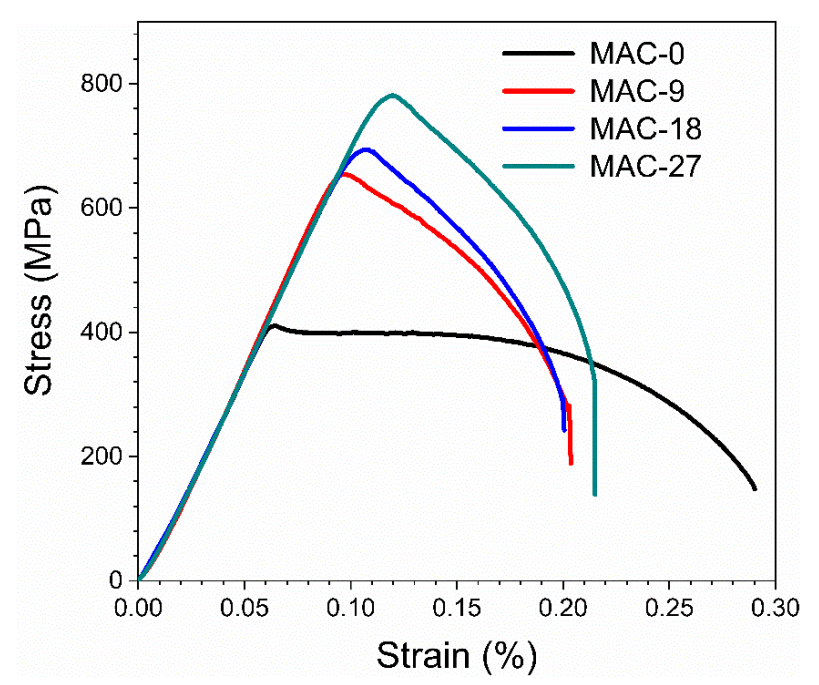

Figure 3. Stress-strain curves.

The yield strength (YS) values of the MAC-9, MAC-18, and MAC-27 samples are approximately $48 \%, 58 \%$, and $76 \%$ higher than that of the MAC- 0 sample, whereas the ultimate tensile strength (UTS) increases by $60 \%, 71 \%$, and $91 \%$, respectively. Normal Hall-Petch relationship can be used to explain the continuous improvement of mechanical properties of MAC samples [13]:

$$
\sigma_{y}=\sigma_{0}+\frac{\mathrm{K}_{y}}{\sqrt{d}} \text { or } H=H_{0}+\frac{\mathbf{K}_{y}^{\prime}}{\sqrt{d}}
$$

where, $\sigma_{\mathrm{y}}$ is yield stress, $H$ is hardness, $d$ is grain size, and $\sigma_{0}, H_{0}$ and $\mathrm{K}_{y}, \mathrm{~K}_{y}^{\prime}$ are constants which are independent of grain size; $\sigma_{0}, H_{0}$ known as frictional stress, frictional hardness respectively, while $\mathrm{K}_{\mathrm{y}}, \mathrm{K}_{\mathrm{y}^{\prime}}$ are slope of the Hall-Petch relation. It was observed that as the size of grains decreases, the hardness and yield stress increases. Therefore, MAC processing significantly affects the mechanical properties of Ti- $45 \mathrm{Nb}$, and this can be attributed to the Hall-Petch hardening caused by severe grain refinement and the strong increase in dislocation density, entanglement makes it difficult for dislocation slippage, and the deformation resistance of the alloy increases. The latter is reflected in the broadening of the XRD diffraction peaks of the samples processed by MAC. In addition, with the increase of strain, and the continuous transformation of strain axis, the heterogeneous microstructure with lower pass times was significantly improved, which also helped to obtain better mechanical response. Compared with the elongation of $19.8 \%$ in the MAC0 sample, after increasing the number of passes from 9 to 27, the elongation decreases, however, the minimum elongation in the MAC sample is still higher than $9 \%$.

Figure 4 depicts typical SEM images of the tensile fracture surfaces of the solid solution and MAC MAC-0, MAC-9, MAC-18 and MAC-27 samples, and the reduction in the area of each micro-tensile sample is calculated (Table 2). Figure 4a-d display the typical ductile fracture dimple morphologies. Compared with the solid solution MAC-0 sample, the dimples of MAC-9, MAC-18 and MAC-27 samples are getting smaller and shallower, and deep dents and holes are also significantly reduced. This may correspond to a significant increase in the tensile strength with fair ductility. 

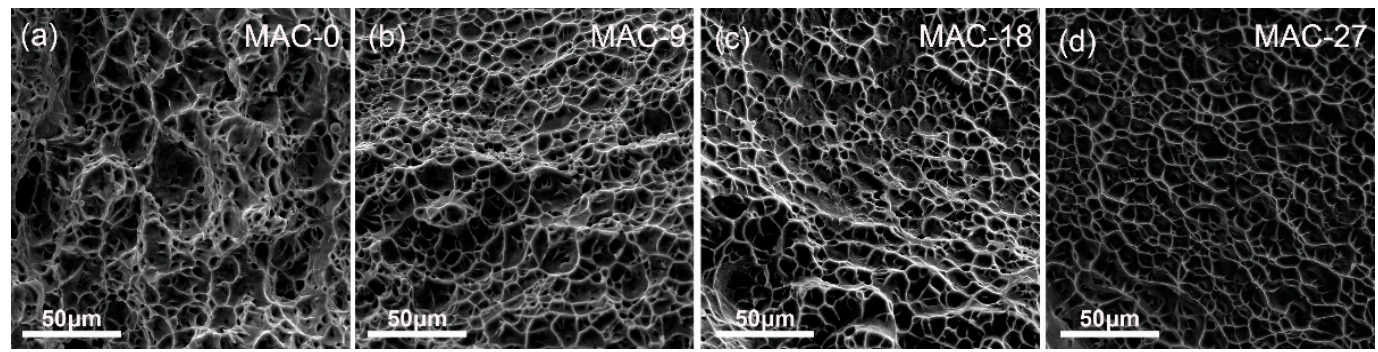

Figure 4. Tensile fracture: (a) solid solution MAC-0 sample, (b) MAC-9 sample, (c) MAC-18 sample, and (d) MAC-27 sample.

\subsection{Fretting Wear Behavior}

\subsubsection{Friction Coefficient}

The dynamic COF curves of the MAC-0, MAC-9, MAC-18, and MAC-27 samples are shown in Figure 5. The average dynamic COF of the samples decreases with decreasing grain size. The COF of the MAC-0 sample is 0.424 , while the MAC-27 sample shows the lowest COF of 0.390 with the reduction of approximately $8 \%$.

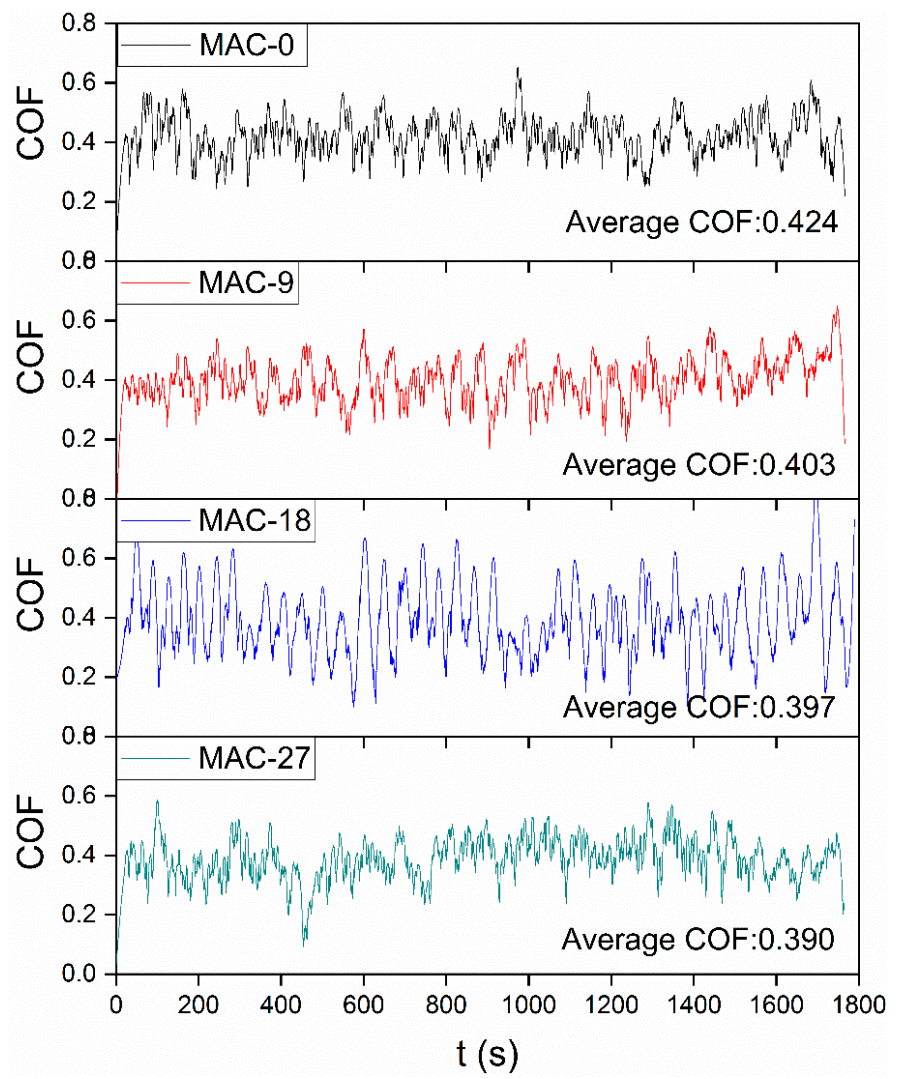

Figure 5. Friction coefficient curves of the Ti- $45 \mathrm{Nb}$ samples.

\subsubsection{Wear Profile and Volume Wear Rate}

To further explore the influence of MAC on the characteristics and mechanism of the fretting wear behavior, five two-dimensional line scans taken perpendicular to the sliding direction were selected equidistantly from the center of each wear scar, and their profiles were measured using the Vision program, as shown in Figure 6a, which also can quantitatively calculate the volume wear rate. The volume wear rates of each sample are shown in Table 2. Figure $6 \mathrm{~b}$ shows the three-dimensional morphology of the wear scars of the MAC-0, MAC-9, MAC-18, and MAC-27 samples. It was observed that the wear scar profile of the MAC-0 sample has the deepest grooves and the widest ridges, which cause the 
largest volume loss, with a maximum volume wear rate of $10.39 \times 10^{-3} \mathrm{~mm}^{3} \cdot \mathrm{N}^{-1} \cdot \mathrm{mm}^{-1}$. Moreover, there are different degrees of accumulation of wear products on both sides of the wear scar, indicating an increasingly worn and uneven profile due to the low shear resistance of the MAC-0 sample that corresponds to the MAC-0 sample in Figure 7a which shows a larger shear ridge. The maximum wear scar depths of the samples processed by MAC are all smaller than that of the MAC-0 sample. As the number of passes increases from 9,18 to 27 , the volume wear rates were reduced by approximately $5 \%, 20 \%$, and $40 \%$, respectively, compared to the MAC-0 sample. In the meanwhile, their wear profiles also tend to have a regular triangular shape, while the widths of the wear profile decrease, indicating a reduction in shear spallation, which is attributed to the increase in the shear resistance of the samples caused by MAC.

(a)
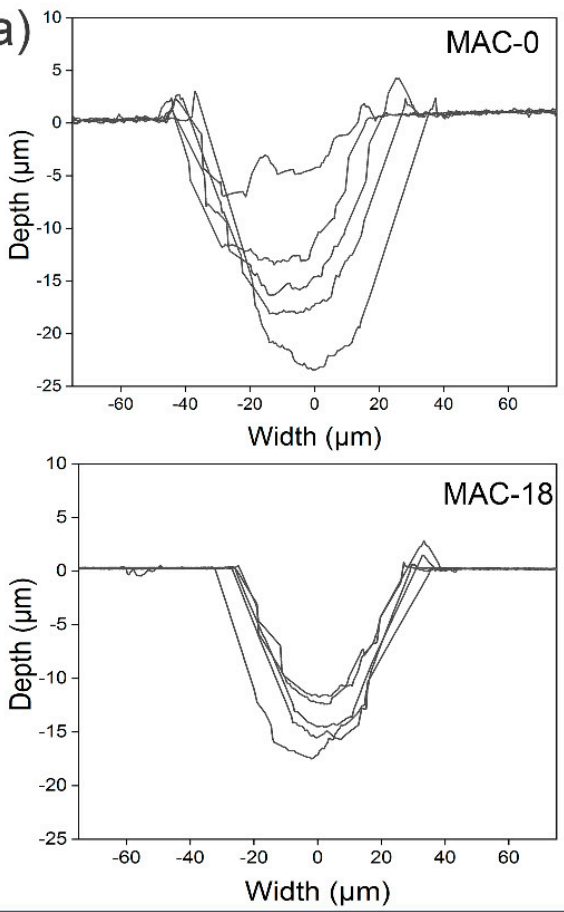

(b)

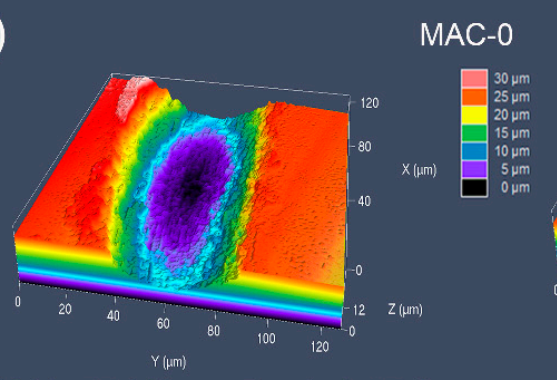

Width: $77.823 \mu \mathrm{m}$, Depth: $25.550 \mu \mathrm{m}$

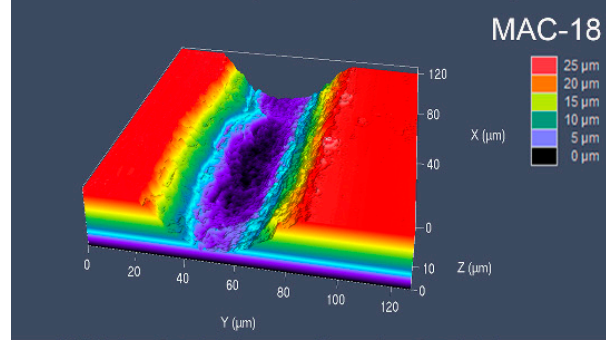

Width: $65.081 \mu \mathrm{m}$, Depth: $17.906 \mu \mathrm{m}$
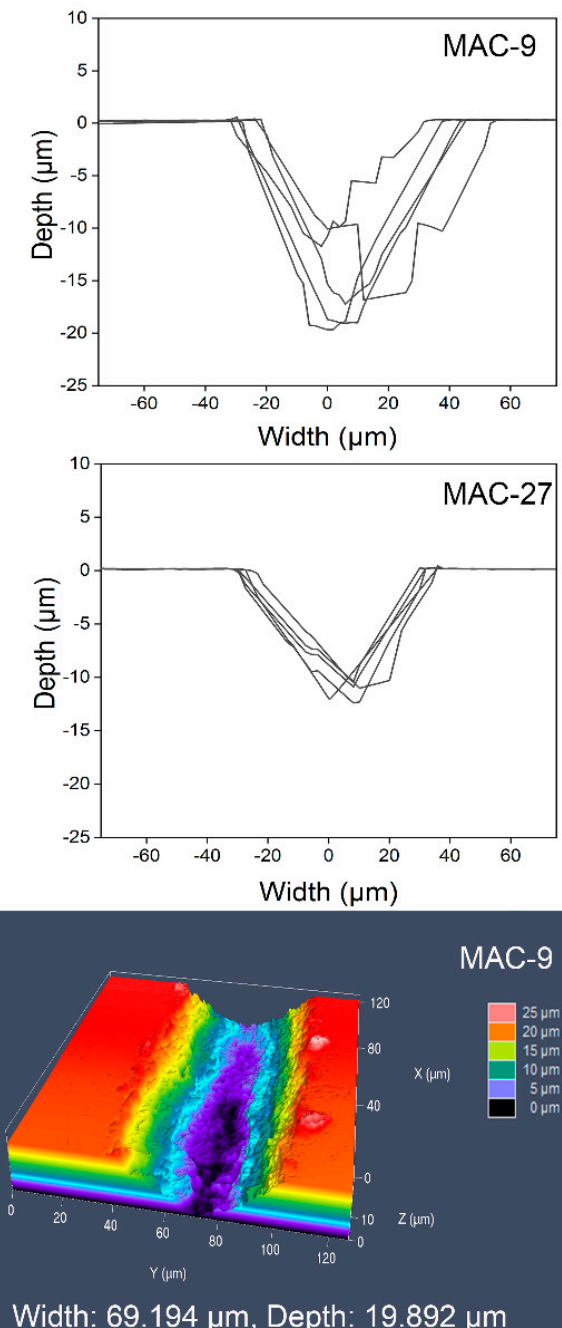

Width: $69.194 \mu \mathrm{m}$, Depth: $19.892 \mu \mathrm{m}$

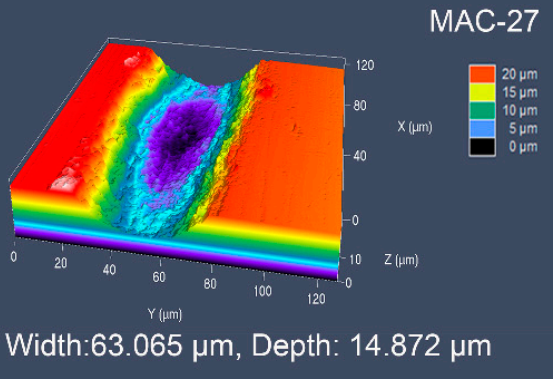

Figure 6. Profiles of the wear scars of the Ti-45Nb samples after fretting: (a) two-dimensional morphology and (b) three-dimensional morphology. 

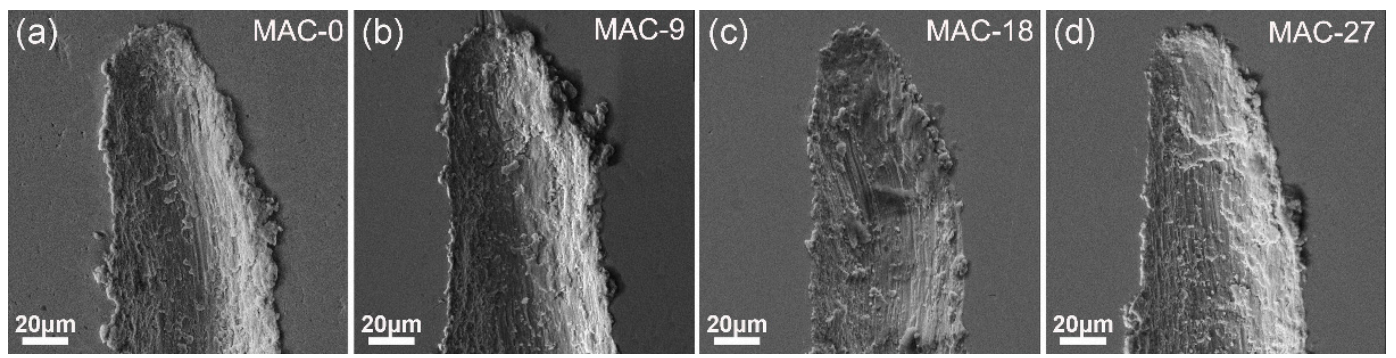

Figure 7. Comparison of the shear tongue: (a) MAC-0 sample, (b) MAC-9 sample, (c) MAC-18 sample, and (d) MAC27 sample.

\subsubsection{Fretting Wear Surface Analysis}

During the fretting wear, the material moves to the end of the wear scar along with the scratch due to plastic deformation, forming a wedge-shaped mark. This wear mode is known as wedge formation or shear-tongue formation [31]. The shear tongues of the MAC-0, MAC-9, MAC-18, and MAC-27 samples are shown in Figure 7a-d. It is easy to observe that with the progression of MAC processing, the deformation resistance increased, and the shear tongue shape became smaller and more uniform. This also corresponds to the improvement in microstructure uniformity brought about by the increase in MAC deformation passes (Figure 2).

The SEM images taken at the center of the sample wear scars are shown in Figure 8a-d. The distributions of the wear scars of samples processed by MAC are more uniform, while a severe shear peeling layer appears in the MAC-0 sample. The image of the wear surface of the MAC-0 sample is shown in Figure 8a. Severe brittle spalling and material transfer, large spalling pits and large-scale wear debris can also be observed, which indicates that severe adhesive wear and fatigue failure occurred. Figure $8 \mathrm{~b}-\mathrm{d}$ show the wear scars of the samples processed by MAC, which are mainly composed of varying degrees of furrows parallel to the sliding direction and slight material transfer, which indicates that the wear mechanism changed to slight abrasive wear and local adhesive wear. It is observed that as the number of processing steps increases, the depth of the furrow also decreases. It is worth saying that the shapes of the wear debris of the samples processed by MAC are also significantly different; the wear debris particles are more fragmented and have a small approximately spherical shapes that tend to be evenly distributed inside the wear scar.
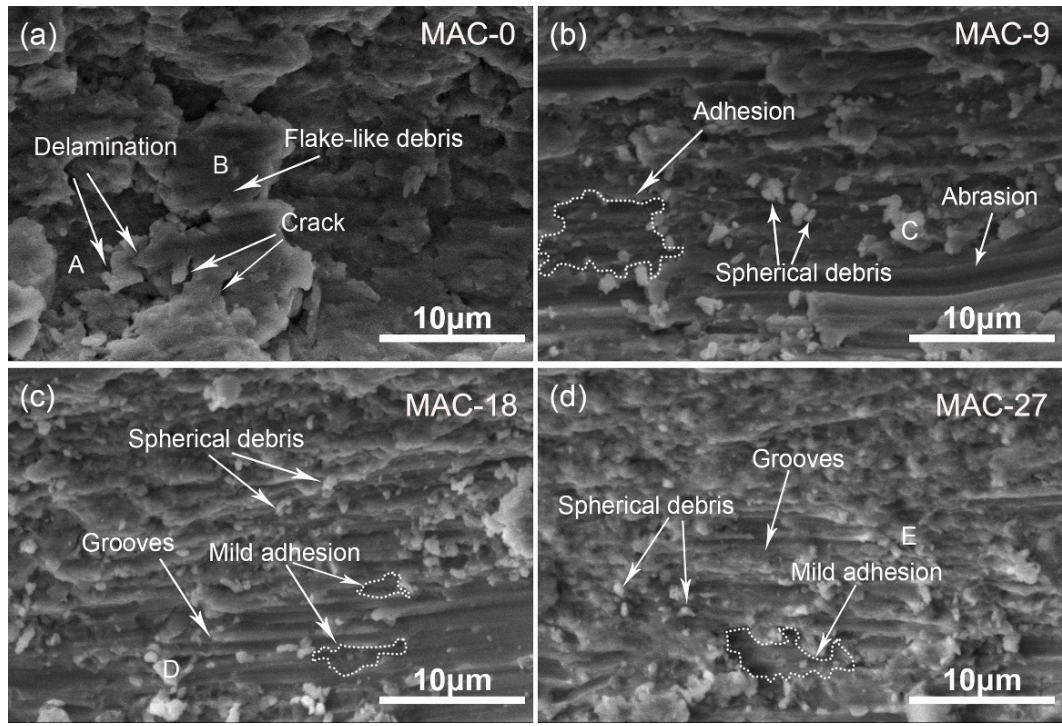

Figure 8. SEM images of the wear scars after the fretting test: (a) MAC-0, (b) MAC-9, (c) MAC-18, and (d) MAC-27. 
To further clarify the severity of adhesive wear and the protective effects of friction oxides, the peeling areas and wear debris particles of the samples were analyzed by energy dispersive spectrometry (EDS). The results are shown in Table 3.

Table 3. Chemical compositions of the wear surfaces detected by EDS in Figure 8.

\begin{tabular}{ccccc}
\hline Region (wt \%) & Ti & Nb & O & C \\
\hline A & 48 & 42 & - & 10 \\
B & 19 & 18 & 31 & 32 \\
C & 44 & 38 & 8 & 10 \\
D & 45 & 37 & 10 & 8 \\
E & 47 & 41 & 12 & - \\
\hline
\end{tabular}

No $\mathrm{O}$ was detected in the peeling part (A) of the MAC-0 sample, indicating that it is a metal peeling layer, which results in a larger wear rate [32], while a higher content of oxide wear debris appeared in the wear scar surface (B), indicating that oxidative wear occurred on the surface of the material and that the oxide did not play a protective role. In addition, the relatively high $\mathrm{C}$ content suggests that seizures may have occurred in this area, indicating poor running-in, and part of the abrasive material from the diamond indenter has also been transferred. $\mathrm{O}$ was detected in the wear debris of the samples processed by $\mathrm{MAC}$, but the amounts of $\mathrm{O}$ were lower than that of the MAC-0 sample, indicating that only slight oxidative wear occurred, which did not play a dominant role in this study. In the analysis of the wear debris of the MAC-27 samples, no C was detected, showing the slightest sticking phenomenon.

There is a switch of wear mechanism after MAC processing. Adhesive wear occurs because the contact surface produces instantaneous high temperatures under the squeezing action of the indenter and produces a hard bonding point with the friction pair, while relative movement continues to occur, under the combined action of the impact force and the shear force, a bonding phenomenon in which point tearing breaks occur causing surface material loss [5]. Considering that there is a certain residual stress in a deformed sample after MAC, as the volume stress can reduce the mobility of metal atoms, numerous experimental results show that the residual stress of the wear surface can reduce the maximum shear stress and equivalent stress on the surface [33], thereby improving the shear resistance of the material surface and helping to reduce the fretting wear.

As plastic deformation continues to accumulate, work hardening occurs. Under the action of alternating stress, fatigue damage occurs on the friction surface. After a crack extends from the subsurface to the surface layer, a whole region of tearing and peeling occurs, resulting in large peeling pits. Typical large-scale wear debris can be observed (Figure 8a), and the size of the flake wear debris is related to the load and the ultimate yield strength, which is mentioned in the delamination theory of Suh [34]:

$$
A=\frac{W}{\sigma_{S}}
$$

where $A$ is the area of the wear debris, $W$ is the load, and $\sigma_{S}$ is the ultimate yield strength. The low strength and good ductility of the MAC-0 sample generated larger wear debris, and the large flake wear debris particles were pushed out of the track once it was formed due to the centrifugal force and they accumulated at the end of the scar. The subsequent wear behavior has a slight impact and cannot act as a third body for protection, causing serious material loss. Fatigue wear is the most serious factor in fretting wear [35], and it accounts for the largest proportion of volume wear. According to Rowe's modified Archard formula [33]:

$$
\frac{d V}{d S}=\mathrm{K}_{\mathrm{m}}\left(1+\alpha f^{2}\right) \beta \frac{W}{\sigma_{S}}
$$


where $K_{m}$ is a coefficient related to material properties, $\alpha$ is a constant, $f$ is a friction coefficient, $\beta$ is a coefficient related to surface properties, $W$ is a load, and $\sigma_{s}$ is the ultimate yield strength. The wear rate is inversely proportional to the ultimate yield strength of the material and the hardness of the material. In this study, the fine-grained Hall-Patch hardening and the increase in dislocation density caused by MAC can effectively hinder crack propagation [36], so that large spalling pits were not easily generated, bringing about significant work hardening that gradually increased the resistance to plastic deformation, thus improving the yield strength and reducing adhesive wear.

Under the same load, the value of the COF is determined by the friction force. The average COF can be used to characterize the lubricity and wear resistance of a material over a period of time. A material with good wear resistance should have a good quality wear running-in surface. According to the adhesion friction theory proposed by Bowden et al. [37], it is believed that the friction force model is composed of two effects, namely, adhesion and furrowing:

$$
F=T+P_{e}=A \tau_{b}+S p_{e}
$$

where $F$ is the friction force, $T$ is the shear force in the friction process, $P_{e}$ is the furrow force, $A$ is the adhesion area, $\tau_{b}$ is the shear strength of the adhesion node, $S$ is the furrow area, and $p_{e}$ is the furrow force per unit area.

A large number of experiments have proven that $\tau_{b}$ is related to the sliding speed and lubrication state, and it is very close to the ultimate shear strength of the softer material in the friction pair. The value of $p_{e}$ is related to the material properties, and the embedded depth of the hard peak decreases with increasing ultimate yield strength of the softer material. Therefore, it can be concluded that the harder the softer material is, the smaller the furrow force.

The decrease in the COF found in this study may correspond to the increase in the yield strength caused by MAC and the decrease in the furrow depth. At the same time, the samples processed by MAC had a better lubrication state during the wear process, which can be explained by the similar research results of Wang [38]. Due to the increased strength and reduced ductility of the samples treated by MAC, the smaller wear debris particles are more likely to stay in the wear track, acting as third bodies, creating a certain isolation between the wear surface and the wear pair and assuming a certain pressure-bearing, lubricating and anti-friction effects [24,39]. Compared with large pieces of wear debris sliding in the wear scar, small wear debris particles roll in the wear track like "balls", causing a decrease in the COF.

\section{Conclusions}

- MAC significantly refined the grain size of the Ti-45Nb alloy and produced UFG microstructures with average grain sizes of approximately $0.3 \mu \mathrm{m}(300 \mathrm{~nm})$ for the MAC-9 sample, $0.2 \mu \mathrm{m}(200 \mathrm{~nm})$ for the MAC-18 sample, and approximately $0.1 \mu \mathrm{m}$ $(100 \mathrm{~nm})$ for the MAC-27 sample compared to the MAC-0 sample with a grain size of approximately $15 \mu \mathrm{m}$. The dislocation density also increased from $7.09 \times 10^{16} / \mathrm{m}^{2}$ to $5.16 \times 10^{18} / \mathrm{m}^{2}$ after 27 passes MAC processing.

- MAC significantly improved the tensile strength and hardness of Ti-45Nb alloys. At the same time, the elongation of all samples remained above $9 \%$, showing good strength and ductility.

- MAC reduced the fretting wear of Ti- $45 \mathrm{Nb}$ samples which can be mainly attributed to the following aspects:

(1) MAC reduced the COF of the samples, indicating that the samples processed by MAC have better lubricity and wear resistance;

(2) MAC reduced the wear rates, which was attributed to the transformation of the wear mechanism in the wear scar: the severe adhesive wear, fatigue wear, and oxidative wear of the MAC-0 sample switch into slight abrasive wear and adhesive wear, accompanied by slight oxidative wear of the MAC sample after 27 passes; 
(3) After MAC processing, the shape of the wear debris in the wear area changed from large-size flakes to small-size spherical debris particles that moved in the form of "rolling" and acted as a third body to bear pressure and reduce friction.

Author Contributions: Conceptualization, X.X., Z.X. and N.H.; methodology, N.H. and Z.X.; validation, Z.X., N.H., and Y.L.; formal analysis, N.H.; investigation, Z.X.; resources, N.H. and X.X.; data curation, Z.X. and Y.L.; writing-original draft preparation, Z.X.; writing-review and editing, Z.X. and N.H.; visualization, Z.X.; supervision, X.X. and N.H.; project administration, X.X.; funding acquisition, N.H. and X.X. All authors have read and agreed to the published version of the manuscript.

Funding: This research was funded by the National Natural Science Foundation of China (No. 31922040), Shenzhen Science and Technology Research Funding (Nos. SGLH20180625144002074 and JCYJ20180507182637685), Youth Innovation Promotion Association of Chinese Academy of Sciences (Nos. 2017416 and 2020353), Natural Science Foundation of Guangdong Province (No. 2018A030313873), Shenzhen-Hong Kong Innovative Collaborative Research and Development Program (No. 9240014), Guangdong-Hong Kong Technology Cooperation Funding Scheme (No. GHP/085/18SZ), as well as Hong Kong Research Grants Council General Research Funds (No. CityU 11205617).

Conflicts of Interest: The authors declare no conflict of interest.

\section{Abbreviations}

The following physical quantities and abbreviations are used in this manuscript.

\begin{tabular}{|c|c|c|}
\hline$A$ & The area of the wear debris & $\mathrm{mm}^{2}$ \\
\hline$A$ & The adhesion area & $\mathrm{mm}^{2}$ \\
\hline $\mathrm{BF}$ & Bright-field & - \\
\hline CG & Coarse-grained & - \\
\hline $\mathrm{COF}$ & Friction coefficient & - \\
\hline $\mathrm{CP}$ & Commercial pure & - \\
\hline$d$ & Grain size & $\mu \mathrm{m}$ \\
\hline DF & Dark-field & - \\
\hline ECAP & Equal-channel angular pressing & - \\
\hline EDS & Energy dispersive spectrometry & - \\
\hline$f$ & Friction coefficient & 1 \\
\hline$F$ & The friction force & $\mathrm{N}$ \\
\hline$h$ & The height after deformation & $\mathrm{mm}$ \\
\hline$h_{0}$ & The original height of the MAC samples & $\mathrm{mm}$ \\
\hline $\mathrm{H}_{0}$ & Hardness constant & $\mathrm{Hv}$ \\
\hline $\mathrm{HPT}$ & High pressure torsion & - \\
\hline ICP-OES & Inductively-coupled plasma optical emission spectrometry & - \\
\hline$K$ & Volume wear rate & $\mathrm{mm}^{3} \cdot \mathrm{N}^{-1} \cdot \mathrm{mm}^{-1}$ \\
\hline $\mathrm{K}_{\mathrm{m}}$ & Material properties dependant coefficient & 1 \\
\hline Ky & A slope of the Hall-Petch relation & 1 \\
\hline$K_{y}^{\prime}$ & A slope of the Hall-Petch relation & 1 \\
\hline MAC & Multi-axial compression & - \\
\hline $\mathrm{OM}$ & Optical microscopy & - \\
\hline$p_{e}$ & The furrow force per unit area & $\mathrm{N} \cdot \mathrm{mm}^{-2}$ \\
\hline$P_{e}$ & The furrow force in the friction process & $\mathrm{N} \cdot \mathrm{mm}^{-2}$ \\
\hline RT & Room temperature & ${ }^{\circ} \mathrm{C}$ \\
\hline$S$ & The total sliding distance & $\mathrm{mm}$ \\
\hline S & The furrow area & $\mathrm{mm}^{2}$ \\
\hline SAED & Selected area electron diffraction & - \\
\hline SEM & Scanning electron microscopy & - \\
\hline SPD & Severe plastic deformation & - \\
\hline$T$ & The shear force in the friction process & $\mathrm{N}$ \\
\hline TEM & Transmission electron microscopy & - \\
\hline
\end{tabular}




$\begin{array}{lll}\text { UFG } & \text { Ultra-fine-grained } & - \\ \text { UTS } & \text { Ultimate tensile strength } & \mathrm{MPa} \\ W & \text { The load } & \mathrm{N} \\ \text { XRD } & \text { X-ray diffraction } & - \\ \text { YS } & \text { Yield strength } & \mathrm{MPa} \\ \alpha & \text { Material dependent constant } & 1 \\ \beta & \text { Coefficient related to surface properties } & 1 \\ \delta & \text { Elongation } & \% \\ \Delta V & \text { The wear volume } & \mathrm{mm}^{3} \\ \varepsilon & \text { Accumulative strain } & 1 \\ \rho & \text { Dislocation density } & \mathrm{m}^{-2} \\ \sigma_{0} & \text { Strength constant } & \mathrm{MPa} \\ \sigma_{s} & \text { Yield strength } & \mathrm{MPa} \\ \sigma_{y} & \text { Yield strength } & \mathrm{MPa} \\ \tau_{b} & \text { The shear strength of the adhesion node } & \mathrm{MPa} \\ \Psi & \text { Reduction of area } & \%\end{array}$

\section{References}

1. Kumar, S.; Nehra, M.; Kedia, D.; Dilbaghi, N.; Tankeshwar, K.; Kim, K. Nanotechnology-based biomaterials for orthopaedic applications: Recent advances and future prospects. Mater. Sci. Eng. C 2020, 106, 110154. [CrossRef]

2. Niinomi, M.; Nakai, M.; Hieda, J. Development of new metallic alloys for biomedical applications. Acta. Biomater 2012, 8, 3888-3903. [CrossRef]

3. Delshadmanesh, M.; Khatibi, G.; Ghomsheh, M.Z.; Lederer, M.; Zehetbauer, M.; Danninger, H. Influence of microstructure on fatigue of biocompatible $\beta$-phase Ti-45Nb. Mater. Sci. Eng. A 2017, 706, 83-94. [CrossRef]

4. $\quad$ Li, Y.; Yang, C.; Zhao, H.; Qu, S.; Li, X.; Li, Y. New Developments of Ti-Based Alloys for Biomedical Applications. Materials 2014, 7, 1709-1800. [CrossRef]

5. Zhou, Z.R.; Zhu, M.H. Composite Frettig Wear; Shanghai Jiao Tong University Press: Shanghai, China, 2004.

6. Geetha, M.; Singh, A.K.; Asokamani, R.; Gogia, A.K. Ti based biomaterials, the ultimate choice for orthopaedic implants-A review. Prog. Mater. Sci. 2009, 54, 397-425. [CrossRef]

7. Sumitomo, N.; Noritake, K.; Hattori, T.; Morikawa, K.; Niwa, S.; Sato, K.; Niinomi, M. Experiment study on fracture fixation with low rigidity titanium alloy. J. Mater. Sci. Mater. Med. 2008, 19, 1581-1586. [CrossRef]

8. Scharf, T.W.; Mogonye, J.E. Tribological properties and mechanisms of self-mated ultrafine-grained titanium. Wear 2017, 376-377, 931-939.

9. Yang, C.; Song, N.; Liao, X.; Song, M.; Zhu, Y. Structural evolutions of metallic materials processed by severe plastic deformation. Mater. Sci. Eng. R-Rep. 2018, 133, 1-59.

10. Starink, M.J.; Qiao, X.G.; Zhang, J.W.; Gao, N. Predicting grain refinement by cold severe plastic deformation in alloys using volume averaged dislocation generation. Acta. Mater. 2009, 57, 5796-5811. [CrossRef]

11. Subramanian, C. Some considerations towards the design of a wear resistant aluminium alloy. Wear 1992, 155, 193-205. [CrossRef]

12. Archard, J.F. Contact and Rubbing of Flat Surfaces. J. Appl. Phys. 1953, 24, 981-988. [CrossRef]

13. Hall, E.O. Variation of Hardness of Metals with Grain Size. Nature 1954, 173, 948-949. [CrossRef]

14. Panigrahi, A.; Sulkowski, B.; Waitz, T.; Ozaltin, K.; Chrominski, W.; Pukenas, A.; Horky, J.; Lewandowska, M.; Skrotzki, W.; Zehetbauer, M. Mechanical properties, structural and texture evolution of biocompatible Ti-45Nb alloy processed by severe plastic deformation. J. Mech. Behav. Biomed. Mater. 2016, 62, 93-105. [CrossRef]

15. Kucukomeroglu, T. Effect of equal-channel angular extrusion on mechanical and wear properties of eutectic Al-12Si alloy. Mater. Des. 2010, 31, 782-789. [CrossRef]

16. Kundu, A.; Kapoor, R.; Tewari, R. Severe plastic deformation of copper using multiple compression in a channel die. Scr. Mater. 2008, 58, 235-238. [CrossRef]

17. Valiev, R.Z.; Islamgaliev, R.K.; Alexandrov, I.V. Bulk nanostructured materials from severe plastic deformation. Prog. Mater. Sci. 2000, 45, 103-189. [CrossRef]

18. Estrin, Y.; Vinogradov, A. Extreme grain refinement by severe plastic deformation: A wealth of challenging science. Acta. Mater 2013, 61, 782-817. [CrossRef]

19. Wang, B.; Liu, Z.; Li, J. Microstructure evolution in AISI201 austenitic stainless steel during the first compression cycle of multi-axial compression. Mater. Sci. Eng. A 2013, 568, 20-24. [CrossRef]

20. Stolyarov, V.V.; Shuster, L.S.; Migranov, M.S.; Valiev, R.Z.; Zhu, Y.T. Reduction of friction coefficient of ultrafine-grained CP titanium. Mater. Sci. Eng. A 2004, 371, 313-317. [CrossRef]

21. La, P.Q.; Ma, J.Q.; Zhu, Y.T.; Yang, J.; Liu, W.M.; Xue, Q.J.; Valiev, R.Z. Dry-sliding tribological properties of ultrafine-grained Ti prepared by severe plastic deformation. Acta. Mater. 2005, 53, 5167-5173. [CrossRef]

22. Long, Y.; Huang, X.; Wang, T. Effect of Grain Refinement on the Fretting Wear Properties of Spark Plasma Sintered TC4 Alloy. Rare. Metal. Mat. Eng. 2015, 44, 1713-1718. 
23. Purcek, G.; Saray, O.; Kul, O.; Karaman, I.; Yapici, G.G.; Haouaoui, M.; Maier, H.J. Mechanical and wear properties of ultrafinegrained pure Ti produced by multi-pass equal-channel angular extrusion. Mater. Sci. Eng. A 2009, 517, 97-104. [CrossRef]

24. Wang, C.T.; Gao, N.; Gee, M.G.; Wood, R.J.K.; Langdon, T.G. Effect of grain size on the micro-tribological behavior of pure titanium processed by high-pressure torsion. Wear 2012, 280-281, 28-35. [CrossRef]

25. Shu, D.L. Mechanical Properties of Engineering Materials; China Machine Press: Beijing, China, 2004.

26. Beake, B.D.; Shi, B.; Sullivan, J.L. Nanoscratch and nanowear testing of TiN coatings on M42 steel. Tribo-Mater. Surf. Interfaces 2014, 5, 141-147. [CrossRef]

27. Beake, B.D.; Liskiewicz, T.W.; Pickford, N.J.; Smith, J.F. Accelerated nano-fretting testing of Si(1 0 0). Tribol. Int. 2012, 46, $114-118$. [CrossRef]

28. Doni, Z.; Alves, A.C.; Toptan, F.; Gomes, J.R.; Ramalho, A.; Buciumeanu, M.; Palaghian, L.; Silva, F.S. Dry sliding and tribocorrosion behaviour of hot pressed CoCrMo biomedical alloy as compared with the cast CoCrMo and Ti6Al4V alloys. Mater. Des. 2013, 52, 47-57. [CrossRef]

29. Völker, B.; Maier-Kiener, V.; Werbach, K.; Müller, T.; Hohenwarter, A. Influence of annealing on microstructure and mechanical properties of ultrafine-grained Ti45Nb. Mater. Des. 2019, 179, 107864. [CrossRef]

30. Williamson, G.K.; Smallman, R.E. III. Dislocation densities in some annealed and cold-worked metals from measurements on the X-ray debye-scherrer spectrum. Philos. Mag. 1956, 1, 34-46. [CrossRef]

31. Kato, K. Micro-mechanisms of wear-Wear modes. Wear 1992, 153, 277-295. [CrossRef]

32. Li, X.X.; Shi, J.F.; Wang, H.X.; Han, B.Q.; Feng, J.; Zhang, B. Role of tribo-layers and tribo-oxides in dry sliding wear process of Ti6Al4V alloy. Surf. Technol. 2019, 48, 245-251.

33. Wen, S.Z.; Huang, P. Principles of Tribology; Tsinghua University Press: Beijing, China, 2008.

34. Suh, N.P. The delamination theory of wear. Wear 1977, 25, 111-124. [CrossRef]

35. Ke, J.; Liu, X.B.; Liang, J.; Liang, L.; Luo, Y.S. Microstructure and fretting wear of laser cladding self-lubricating anti-wear composite coatings on TA2 alloy after aging treatment. Opt. Laser. Technol. 2019, 119, 105599. [CrossRef]

36. Zhou, L.; Liu, G.; Han, Z.; Lu, K. Grain size effect on wear resistance of a nanostructured AISI52100 steel. Scr. Mater. 2008, 58, 445-448. [CrossRef]

37. Bowden, F.P.; Tabor, D.F. The friction and lubrication of solids. Am. J. Phys. 1951, 19, 428. [CrossRef]

38. Wang, L.; Zhang, Q.Y.; Li, X.X.; Cui, X.H.; Wang, S.Q. Dry Sliding Wear Behavior of Ti-6.5Al-3.5Mo-1.5Zr-0.3Si Alloy. Metall. Mater. Trans. A 2014, 45, 2284-2296. [CrossRef]

39. Hou, B.; Huang, W.J.; Chen, B.S.; Zhou, Z.R.; Li, C.S. Fretting wear mechanisms of AZ91D magnesium alloy in slip regime AZ91D. Tribology 2004, 24, 351-354. 